\title{
Los procesos político-comunicacionales de una organización indígena en Salta, Argentina
}

The political-communicational processes of an indigenous organization in Salta, Argentina

\author{
Emilia Villagra \\ Instituto de Estudios en Comunicación, Expresión y Tecnologías \\ Consejo Nacional de Investigaciones Científicas y Técnicas \\ Universidad Nacional de Córdoba, Argentina \\ emivillagra93damail.com \\ https://orcid.org/0000-0002-5639-7997
}

\section{Resumen}

El artículo analiza los procesos político-comunicacionales de la Organización de Comunidades Aborígenes de Nazareno (OCAN), situada en la provincia de Salta, Argentina, atendiendo a prácticas de intervención y articulación con actores religiosos y estatales. En términos teóricos, plantea un abordaje de los Estudios sobre Comunicación Popular y su relación con investigaciones sobre experiencias audiovisuales de pueblos indígenas. Al mismo tiempo, recupera aportes de la Antropología interesados en indagar en el vínculo entre prácticas mediáticas y procesos de emergencia étnica. En términos metodológicos, se orienta sobre una perspectiva etnográfica, recurriendo a la observación participante, la entrevista abierta y la participación en asambleas y talleres de comunicación. Los resultados señalan que, en el marco de los procesos políticos de la organización indígena, y especialmente a partir de la creación de su radio comunitaria FM OCAN, es posible identificar una relación entre proyectos de comunicación popular, lucha por el territorio y reivindicaciones identitarias.

Palabras clave: comunicación indígena, prácticas políticas, radio, identidad, territorio.

\begin{abstract}
The article analyzes the political-communicational processes of the Organization of Aboriginal Communities of Nazareno (OCAN), located in the province of Salta, Argentina, attending to practices of intervention and articulation with religious and state actors. In theoretical terms, it proposes an approach to Popular Communication Studies and its relationship with research on audiovisual experiences of indigenous peoples. At the same time, it recovers contributions from Anthropology interested in investigating the link between media practices and processes of ethnic emergence. In methodological terms, it is oriented on an ethnographic perspective, resorting to participant observation, open interviews and participation in assemblies and communication workshops. The results indicate that, within the framework of the political processes of the indigenous organization, and especially since the creation of its community radio FM OCAN, it is possible to identify a relationship between popular communication projects, the struggle for territory and identity claims.
\end{abstract}

Keywords: indigenous communication, political practices, radio, identity, territory. 


\section{Introducción}

El presente artículo indaga sobre los procesos político-comunicacionales de una organización indígena del pueblo kolla': la Organización de Comunidades Aborígenes de Nazareno (OCAN), ubicada en el municipio de Nazareno, provincia de Salta (Argentina). Allí se creó, en el año 2016, la radio comunitaria FM OCAN. Desde 1980, las dimensiones políticas, económicas e institucionales del proyecto político-comunicacional de la OCAN fueron articuladas con el trabajo que realizaba la Obra Claretiana para el Desarrollo $(\mathrm{OCLADE})^{2}$ y, posteriormente, el Programa Social Agropecuario (PSA) ${ }^{3}$, por medio de una serie de programas y proyectos para el desarrollo local. Originalmente, el interés era fortalecer la cultura kolla a partir de una reconstrucción de la historia local. Al mismo tiempo, estos proyectos buscaban profundizar en mejoras tecnológicas para garantizar el "progreso" en zonas rurales con un énfasis higienista e integracionista. En un segundo momento, irrumpieron nociones como las de comunicación popular y comunitaria que conllevaron el desarrollo de programas más bien educativos, orientados a la construcción de redes con Universidades Nacionales y al aprendizaje del lenguaje gráfico y radiofónico. Desde entonces, el proceso comunicacional comenzó a abordarse desde aspectos vinculados a la comunicación popular, alternativa y comunitaria, con el objetivo de consolidar una "radio propia" que contemplara demandas e intereses de la OCAN.

En términos metodológicos, el trabajo se orienta sobre métodos cualitativos, recurriendo a la observación participante, la entrevista abierta y la participación en asambleas y talleres de comunicación. Al mismo tiempo, utilizamos la perspectiva etnográfica (Guber, 2001) en tanto instancia empírica y de intervención, pero también como práctica de reflexión posterior al trabajo de campo que permitió sistematizar notas, estudiar y analizar la complejidad de los procesos, las relaciones y las dinámicas de la organización indígena en el periodo 2014-2019. Este método de conocimiento nos permitió comprender las disputas "hacia dentro", los debates y negociaciones entre nuestros interlocutores y agentes externos a la comunidad. Al mismo tiempo, fue útil para indagar en dos periodos histórico-políticos diferentes que estuvieron vinculados al financiamiento de la política pública en materia comunicacional y a los espacios de diálogo entre el Estado y los pueblos indígenas.

Cuando empezamos a trabajar con la OCAN en el año 2014, su proyecto comunicacional se encontraba en pleno auge ya que la coyuntura durante el gobierno de Cristina Fernández de Kirchner fomentaba la subvención de medios comunitarios, populares, alternativos e indígenas, especialmente a partir de la aprobación de la Ley de Servicios de Comunicación Audiovisual (LSCA). Posteriormente, entre el 2015 y 2019, aquella promoción de subsidios, relacionada a la creación de medios y a la sostenibilidad de los mismos, decayó y generó dificultades de sustentabilidad en gran parte de las radios y televisoras existentes. A pesar de los vaivenes de este escenario, durante la transición de ambos periodos, la OCAN logró poner en funcionamiento su emisora. En el periodo kirchnerista pudo acceder a una frecuencia radioeléctrica y a financiamiento para comprar equipamiento. Luego, en el gobierno de Mauricio Macri, inauguró su radio y continuó tejiendo redes con determinados actores que fomentaban el acceso a la comunicación como un derecho. Sin embargo, la importancia estratégica del uso de los medios estuvo presente desde mucho tiempo antes, con diferentes intereses, perspectivas y enfoques, pero siempre vinculados a la posibilidad de ampliar los espacios de información y comunicación en Nazareno.

En este artículo, analizamos los procesos político-comunicacionales de la OCAN identificando prácticas de intervención y articulación con agentes religiosos y estatales. Para ello, en primer lugar, desarrollamos el marco teóricometodológico por medio del cual abordamos las nociones de comunicación popular, alternativa, comunitaria y su relación con experiencias de medios audiovisuales indígenas. En segundo lugar, recuperamos las intervenciones y los programas ejecutados por OCLADE y los técnicos territoriales del PSA con el fin de reconstruir los procesos político-comunicacionales de la organización. Finalmente, analizamos la creación de la radio propia, la FM OCAN, poniendo el foco en los sentidos construidos y disputados en torno a la lucha por el territorio y la identidad indígena kolla. 


\section{Análisis de la comunicación indígena: popular, rural, campesina y en vinculación con las luchas territoriales}

A partir del contexto político suscitado en la década de 1970, empezó a configurarse lo que podríamos denominar un campo académico específico vinculado a los estudios sobre Comunicación Popular albergando gran parte de estas prácticas. En Argentina, las primeras experiencias se visibilizaron en ese mismo periodo, vinculadas al movimiento obrero y a los partidos políticos y desarrolladas con ciertas especificidades en los modos de concebir sus proyectos político-comunicacionales, pero acentuadas en un horizonte participativo y democratizador (Kejval, 2009; Pulleiro, 2012).

Este enfoque se consolidó durante la década de 1980 en base a los aportes de autores como Mario Kaplún, María Cristina Mata, Regina Festa y Jesús Martín-Barbero. Estos autores señalaban la importancia de profundizar en un campo de estudios que analizara la complejidad de las prácticas de comunicación popular frente a la mercantilización de la vida social (Mata, 2015). En este contexto, en el cual la comunicación empezaba a desplazar su foco de atención luego de la publicación de De los medios a las mediaciones (Martín-Barbero, 1983) y de las críticas de Schmucler (1984) al paradigma "comunicación y cultura”, el interés de estos estudios comenzó a pensar a las relaciones de poder, la cultura y la comunicación como procesos articulados. En términos de Martín-Barbero (1987), “cambiar el lugar de las preguntas" (p.11) implicaba analizar los procesos comunicacionales por fuera de una perspectiva culturalista, incorporando a las mediaciones y a los sujetos como parte de las prácticas sociales.

En base a estas contribuciones, el campo de los estudios sobre comunicación popular, alternativa y comunitaria, se consolidó con ciertas definiciones ambiguas que, lejos de sintetizarse en respuestas totalizadoras, refieren a la construcción identitaria y política de cada proyecto comunicacional (Kejval, 2009). Sin embargo, estas nociones también contemplaron algunos criterios como consenso general sobre la base de determinadas lógicas y maneras de ejercer el periodismo para abordar la desigualdad social. Se trataba de una perspectiva de resistencia cultural y activismo que "aparece por exigencias del proceso político y no como instrumento capaz de transformar por sí la realidad social" (Festa et al, 1986, p. 29).

En el marco de estos estudios, en términos metodológicos, resulta sumamente interesante recuperar la propuesta de Patricia Fasano (2015) quien se pregunta, a partir de su propia experiencia empírica, si aquella bibliografía hegemónica que teorizaba sobre estos procesos comunicacionales populares ihacía alusión a un listado de prácticas comunicacionales definidas por sus capacidades alternativas del orden político o al sujeto de la comunicación, fueran cuales fuesen las prácticas? El cuestionamiento de la autora señala que el uso de categorías teóricas definidas de antemano le impedían "ver más allá" y también "escuchar cualquier cosa por fuera de esos códigos", reconociendo un problema epistemológico en el cual su propia investigación encuadraba. A partir de allí, Fasano (2015) se propuso trabajar desde "un "molde" más acorde" en alusión a la incorporación y el uso de herramientas metodológicas que le permitieran construir en situación, es decir, respetando el proceso de conocimiento e investigación sin caer en relativizaciones. Ese lugar fue la etnografía, un enfoque que, para la autora, estaba "preñado de comunicación (dialógica)" (pp. 2-4).

Así, desde una perspectiva etnográfica, la práctica de la investigación en comunicación social y, más aún, para el terreno de las prácticas de comunicación popular, alternativa y comunitaria, se constituiría desde el conocimiento dialógico y la perspectiva de sus miembros. En tal sentido, los aportes fundamentales de Rosana Guber (1991; 2001) a la construcción de un método etnográfico antropológico, habilitan el ejercicio de una práctica de conocimiento que, independientemente de las técnicas de recolección de información, considera las percepciones, emociones y afectividades de los sujetos de la investigación en cuestión.

Respecto de los estudios comunicacionales vinculados al análisis de las prácticas políticas de pueblos indígenas en Argentina, encontramos re- 
laciones, tanto teóricas como metodológicas, vinculadas al desarrollo de experiencias que aparecen referenciadas indistintamente como medios comunitarios, populares o alternativos (Lizondo, 2015; Doyle, 2013, 2016; Siares \& Belotti, 2018; Andrada, 2019). En el marco del desarrollo teóricometodológico de este campo, identificamos que las experiencias comunicacionales de pueblos indígenas aparecen incluidas en dichos estudios, aunque referenciadas en su mayoría como populares, mineras, campesinas o rurales. Según Doyle (2013), desde mediados de 1980 y principios del 2000, estas prácticas comenzaron a reivindicar a la "indigeneidad" y a articular demandas vinculadas a las disputas por los territorios. Esto coincide también con la constitución de las primeras redes de comunicadoras y comunicadores de medios indígenas latinoamericanos, que cobró centralidad como estrategia de visibilización en todo el continente.

A partir de allí, y en vinculación con otras disciplinas, especialmente con la antropología, identificamos un campo de estudio, el de la comunicación indígena, que emergió a fines del siglo XX y resulta útil recuperar para problematizar los procesos político-comunicacionales, las relaciones interétnicas y las configuraciones identitarias de los pueblos indígenas. Puntualmente en Argentina, estos estudios asumen la presencia de los pueblos indígenas en el espacio público mediático como parte de los procesos de emergencia étnica y de las políticas de identidad. Problematizan procesos históricos de larga duración y su estrecha vinculación con el mito de la Argentina blanca y europea, y una tendencia a la homogeneización de las identidades indígenas (Gordillo \& Hirsch, 2010). Además, analizan las disputas identitarias, los reclamos por las tierras, las alianzas y los modos de hacer política por las organizaciones y/o comunidades (Salazar, 2002; Guzmán, 2011; Noro, 2012; Lizondo, 2015, 2017; Doyle, 2016, 2018; Siares \& Belotti, 2018; Belotti, 2018; Andrada, 2019).

Este campo ofrece una dimensión de análisis que permite comprender no sólo el uso de los medios audiovisuales, sino también la complejidad histórica de los procesos políticos de estos pueblos, sus luchas y reivindicaciones actuales. Desde allí elegimos analizar la experiencia político-comunicacional de la OCAN, articulando proyectos de comunicación popular y reivindicaciones en torno a “lo kolla”4.

\section{Las primeras radios en Nazareno: usos comunes de dispositivos tecnológicos de comunicación para el desarrollo}

En el municipio de Nazareno, donde las condiciones geográficas complejizan los desplazamientos y las actividades de las veintitrés comunidades que integran la $\mathrm{OCAN}^{5}$, los medios para comunicarse son escasos y limitados. La radio ha logrado constituirse como el único instrumento de información que conecta instituciones municipales y provinciales, comunicando sobre temáticas diversas.

Desde la década de 1980, cuando comenzó a implementarse el programa de APS por medio de la OCLADE y la gran mayoría de las comunidades no contaban con luz eléctrica, se montó una red de radios de comunicación cuya modulación era la Banda Lateral Única (BLU). Esta red poseía la ventaja de transmitir señales de frecuencias con un consumo bajo de energía y se conectaba mediante baterías y paneles solares que se unían con el hospital municipal y una central del Ministerio de Salud de la Provincia de Salta. A medida que los puestos sanitarios fueron ampliándose en todo el municipio, estos equipos eran los únicos medios que enlazaban al pueblo con el exterior y se utilizaban específicamente para transmitir novedades y urgencias médicas desde las comunidades más alejadas. A fines del siglo $X X$, en el marco de los proyectos técnicos y productivos para alcanzar ciertos estándares del desarrollo que promovía el PSA, dieciocho de las veintitrés comunidades que integran la OCAN contaban con radios BLU. De este modo, ciertas prácticas higienistas comenzaron a ponerse en marcha a través del trabajo de los agentes sanitarios, quienes realizaban consultas mediante la radio, informando sobre fechas de controles y posibles partos, planificando derivaciones hospitalarias en caso de complicaciones y organizando los ficheros médicos de toda la población.

Paralelamente a la construcción de esta red intercomunicativa, a principios del 2000, la comunidad de Cuesta Azul la doce kilómetros de Nazarenol instaló la primera radio de baja potencia en la Escuela Primaria “Fray Mamerto Esquiú”. La misma comenzó desempeñándose como un espacio abierto a la comunidad en general y, luego, se transformó en una herramienta de uso exclu- 
sivamente escolar, en una Radio Escuela. Funcionaba con un motor a gasolina y contaba con una transmisión de aproximadamente tres horas, consumiendo alrededor de tres litros de combustible por día. Por esta razón, la programación diaria se extendía aproximadamente en la franja horaria de 13 a 15 horas $y$, en algunas ocasiones, de 20 a 21 horas (Martínez, Müller \& Rubino, 2007). Al mismo tiempo, en ese mismo periodo, se había instalado en el centro de Nazareno una radio de frecuencia modulada que dependía de la municipalidad.

Durante este periodo, los proyectos que se ejecutaban en materia comunicacional siempre estaban vinculados al trabajo de los agentes sanitarios y los técnicos territoriales. Dada la situación de "aislamiento", la preocupación de OCLADE, el PSA y la OCAN, se relacionaba con las escasas posibilidades de contar con una estructura de salud cubierta por médicos, enfermeros, bioquímicos, odontólogos, radiólogos, choferes de ambulancia, entre otros. Para ello, como parte del fortalecimiento sanitario, se implementó el Proyecto de Desarrollo de la OCAN durante los años 2005 y 2006, financiado por el Instituto Nacional de Asuntos Indígenas (INAII. El mismo contaba con el asesoramiento de los técnicos del PSA, quienes se ocupaban de relevar la situación sanitaria de cada comunidad y solicitar equipos fotovoltaicos que mejoraran el sistema de alimentación de las radios BLU. El proyecto contaba con la realización de algunos talleres de operación básica y mantenimiento de los equipos de comunicación, los cuales eran dictados por el personal del Hospital de Nazareno. Allí, además, se establecía un convenio para la coordinación de los equipos BLU y las radios del Ministerio de Salud Pública, por medio del cual se disponían los horarios de transmisión para elevar los informes semanales y organizar actividades.

\subsection{Entre prácticas de intervención y proyectos de comunicación popular: hacia un "periodismo campesino" y una "radio propia"}

Con el objetivo de trabajar en pos de la creación de una radio que fuera exclusivamente propia de la organización y que contara con mayor potencia, la OCAN comenzó a buscar recursos para implementar estrategias de información que difundieran el trabajo organizacional y las primeras acciones por la disputa territorial. En este sentido, a la par de la construcción y el fortalecimiento del sistema de red de radios BLU y la instalación de las dos primeras emisoras que mencionamos, la organización comenzó a trabajar en un nuevo proyecto comunicacional articulado con estudiantes de la Universidad Nacional de Córdoba y el PSA.

Desde el año 2003, en el marco de las primeras asambleas de la OCAN y con la participación del PSA, se empezó a discutir la posibilidad de trabajar aspectos de "comunicación popular", "periodismo campesino", "derecho indígena”, “legislación nacional y provincial" y "experiencias de organizaciones campesinas" que fortalecieran aspectos "identitarios" y de "revalorización cultural" (Actas de asambleas OCAN, 2003). En ese contexto, los procesos de reconocimiento, tanto en clave política como jurídica, fueron los criterios centrales que impulsaron a que la organización fortaleciera aspectos culturales e identitarios. Las discusiones en las asambleas planteaban que era necesario desarrollar proyectos de comunicación que profundizaran en una agenda informativa local y en la difusión de marcos normativos de Derechos Humanos de pueblos indígenas 6 .

A partir de allí, el PSA decidió incorporar entre sus áreas de trabajo el problema comunicacional de la zona y comenzó a realizar talleres de periodismo campesino mediante sus técnicos territoriales y algunos delegados de la organización. En cierto sentido, esto se planteaba también debido a la falta de comunicación entre las comunidades, lo que era criticado por los habitantes de Nazareno ya que consideraban que las decisiones se centralizaban entre los técnicos y líderes indígenas. Además, las comunidades demandaban mayor profundización respecto al "tema comunicación" no sólo como política de promoción social y comunitaria en términos sanitarios, sino también como una dimensión que fortaleciera y visibilizara voces propias.

En este contexto, mediante un convenio entre el PSA y la Universidad Nacional de Córdoba (UNC). se realizó el proyecto “Capacitación y puesta en marcha de los espacios comunicacionales del Municipio de Nazareno" por medio del Programa de Becas de la Secretaría de Extensión de dicha universidad. Este incluía la realización de un relevamiento y un diagnóstico sobre las posibilidades 
locales de desarrollar sus propios medios, estableciendo relaciones entre las instituciones, las organizaciones y la municipalidad. La intervención estuvo a cargo de estudiantes de la carrera de comunicación social y bajo la coordinación de María Cristina Mata.

Por medio de estos talleres, los habitantes del municipio comenzaron a recibir capacitaciones en dos estilos de comunicación, gráfica y radial, además del aprendizaje sobre operación técnica, locución y gestión de medios. Los estudiantes de la UNC, dotaban de material bibliográfico referido al tema y se ocupaban de llevar propuestas de programación para incentivar a que los habitantes se animaran a participar de los encuentros. A su vez, los talleres se enfocaban en trabajar aspectos de la "comunicación popular" y trataban de fortalecer los debates en torno a la "construcción de un medio propio", lo que implicaba que "reflejara las problemáticas de la comunidad desde la propia experiencia y voces de sus habitantes" (Martínez, Müller \& Rubino, 2007, p. 67). Como resultado de estos talleres, un grupo de personas que participaba de los encuentros empezó a producir un programa en la FM municipal denominado "La Voz Joven". Este trataba sobre temáticas de interés local, música, deporte y noticias de la zona.

Esto derivó en que, paralelamente a las actividades organizadas entre la Universidad y la OCAN, la organización comenzó a editar con fondos propios dos medios gráficos: un periódico mural y un boletín bimestral. El primero, llamado Kitaj, en aymara “Quiero saber más”, brindaba información general, campañas de salud y noticias locales. Este dejó de editarse al cabo de un año, mientras que el segundo, también a cargo de la OCAN y con el mismo nombre, informaba sobre debates y resoluciones de las asambleas de la organización. Sin embargo, al igual que el primero, dejó de producirse por los costos que implicaba su sostenimiento. Además, a esto se le sumaba dos limitaciones no menos importantes. Una de ellas vinculada a la distribución, la cual era muy compleja dada las distancias entre comunidades. El otro aspecto a considerar era que, al ser un medio escrito, su difusión se reducía sólo a aquellos que sabían leer, considerando que parte de la población era analfabeta.

En este contexto, a partir de estas experiencias de comunicación, la posibilidad de proyectar la insta- lación de una radio propia se transformó en una apuesta más ambiciosa, ya que su alcance, recepción y costos favorecía la ampliación de la llegada de la OCAN hacia otras comunidades del municipio. A esto se sumaba el hecho de que las prácticas radiofónicas en Cuesta Azul habían motivado el interés por trabajar desde un perfil comunitario y un uso colectivo: incorporando contenidos sobre la producción agrícola que realizaban en la zona, discusiones asamblearias, proyectos gestionados y ejecutados por los dirigentes de la OCAN y avances respecto a las demandas jurídicas por las tierras que en ese entonces comenzaban a llevarse a cabo. Sin embargo, al ser una Radio Escuela, limitaba las posibilidades de uso organizacional, además de la distancia y la baja potencia que tenía el medio. Esto mismo sucedía con la emisora de la municipalidad, la cual dependía de la buena relación entre la intendencia y la OCAN, algo que variaba según la coyuntura política.

Aun así, las actividades que se realizaron en el marco de los talleres articulados con la UNC continuaron hasta el 2006. Además, no se limitaban simplemente a un uso educativo o informativo, sino que también se realizaban rondas de discusiones sobre "la problemática de la identidad" y "la tierra" (Martínez, Müller \& Rubino, 2007, p. 104). Acorde al momento que atravesaba la organización, recientemente constituida y conjugando acciones con localidades vecinas ${ }^{7}$, los debates por la creación de una radio propia comenzaron a discutir la necesidad de incluir contenidos sobre la situación territorial del Pueblo Kolla y de otros pueblos indígenas de Argentina.

En cierto modo, estos proyectos continuaban insistiendo en la búsqueda por reivindicar y articular aspectos identitarios, culturales y de los derechos indígenas. Sin duda, estas acciones se profundizaron a partir de las prácticas de intervención de los claretianos y los técnicos territoriales. Luego, los proyectos comenzaron a concebir a la comunicación como una estrategia circunscripta a las posibilidades y límites de las luchas que estaba llevando a cabo la organización. Allí, comenzó a articularse la lucha por el territorio como la dimensión más importante a desarrollar en los medios. Esto implicaba visibilizar las demandas protagonizadas por las comunidades indígenas, transformando a estos espacios comunicacionales en ámbitos de referencia política. 


\section{La trayectoria de la FM OCAN: acerca de la dimensión política, económica e institucional del proyecto}

A partir del año 2009, el Estado comenzó a otorgar mayor financiamiento y a brindar capacitaciones en comunicación, dada la coyuntura política de la LSCA que estableció el incentivo a la gestión de medios comunitarios, populares, alternativos e indígenas. En el caso de las radios campesinas y de pueblos originarios, la convergencia entre instituciones estatales y organizaciones sociales significó un momento bisagra, ya que afianzó la apuesta por crear una radio propia.

En Nazareno, en el año 2009, la organización inició los trámites para gestionar la autorización como emisora de pueblo originario representando un hito fundamental en su historia. En este contexto, los vínculos construidos entre la Secretaría de Agricultura Familiar (ex PSA) y la OCAN estaban consolidados, mientras que OCLADE daba un paso al costado, considerando que OCAN había alcanzado la madurez para continuar trabajando autónomamente. De este modo, la construcción de un sentido común para sostener líneas de acción en torno a la futura emisora, implicó una profundización en la articulación con distintos actores. Allí la OCAN amplió su búsqueda de recursos no sólo para obtener recursos económicos, sino para diseñar estrategias en torno a la sostenibilidad institucional del medio.

A partir del año 2012, en el marco de nuevos convenios entre el Estado nacional y las delegaciones provinciales de la Subsecretaría de Agricultura Familiar (SsAF), la provincia de Salta se sumó a implementar, por medio de dicho organismo, el programa denominado "Radios comunitarias rurales. Comunicarnos fortalece". Desde entonces, contó con diversas iniciativas estatales que buscaron conjugar los vínculos ya establecidos y proveer de apoyo económico e institucional a las organizaciones sociales, sobre todo rurales. Por ejemplo, en ese periodo, se conformó la Mesa de Gestión de la Comunicación Popular de Salta y Jujuy, integrada por diversos organismos estatales, entre ellos la SsAF. En Nazareno, gran parte de las iniciativas que se implementaron para montar la FM OCAN, fueron articuladas a través de la Mesa, especialmente por intermedio del trabajo de los técnicos de la SsAF.
En este sentido, y a partir de esto, una de las iniciativas que integró la OCAN fue la Red de Corresponsales Comunitarios, un espacio creado a través de un convenio entre Radio Nacional Salta y Autoridad Federal de Servicios de Comunicación Audiovisual (AFSCA), denominado "Corresponsales. Voces comunitarias en la radio pública". Este tenía como objetivo formar comunicadores rurales que quisieran trabajar en la radio nacional, enviando reportes semanales con noticias de la zona.

Paralelo a estos encuentros, se implementaron dos proyectos financiados por AFSCA: gestión de medios comunitarios y producción radiofónica. El primero de ellos contó con la participación de una integrante de la Coordinadora de Comunicación Audiovisual Indígena (CCAIA) que abordó aspectos de la "comunicación con identidad". El segundo se trató de la producción de un informativo semanal denominado La Pitajlla.

Al mismo tiempo, la Defensoría del Público, a través de la Dirección de Capacitación y Promoción, también dictaba talleres sobre lenguaje radiofónico, operación técnica y edición digital, los cuales lograron distribuirse entre tres comunidades: Nazareno, Cuesta Azul y Campo la Cruz. Esto respondía a una demanda explícita de OCAN, quienes solicitaban que las actividades se coordinaran con las instituciones educativas para motivar la colaboración tanto de maestros como de niños y jóvenes. Allí, en torno al fortalecimiento de la radio propia, se trabajaba con contenidos vinculados a la cosmovisión andina, los derechos de los pueblos indígenas, educación intercultural, noticias locales y regionales, recetas de comidas típicas de la zona y labores relacionadas a la agricultura.

En suma, estos encuentros fueron los principales espacios donde la organización debatió no solo aspectos culturales, sino también objetivos y estrategias claves respecto a la sostenibilidad del proyecto. Entre ellas: cómo participar en convocatorias para obtener subsidios, construir redes para profundizar en capacitaciones técnicas, ofrecer el espacio publicitario de la radio tanto a locales comerciales como a candidatos políticos del municipio, sostener un equipo de comunicadores que no sólo se ocupara de organizar la grilla semanal sino, también, de llevar adelante la sustentabilidad de los costos fijos. 
Como veremos en el próximo apartado, a partir del año 2016, luego de la inauguración de la FM OCAN, los usos de la radio y las estrategias vinculadas a las cambiantes coyunturas renovaron la búsqueda de recursos, abriendo camino a construir nuevas alianzas entre actores internos y externos a la comunidad.

\subsection{Comunicar con identidad: confluencias entre comunidad, política y tierra}

A partir del año 2016, dada la nueva coyuntura política a raíz de la asunción de la Alianza Cambiemos en la Presidencia de la Nación, el contexto denotaba cierto aire de desconfianza y la organización no ignoraba, y de hecho lo discutía en sus asambleas, que pronto las relaciones con el Estado comenzaron a renovarse bajo otras reglas de juego. Esto también se relacionaba con las modificaciones por decreto que sufrió la LSCA en diciembre del 2015, lo que provocó que la OCAN se apurara a poner en funcionamiento su medio ante el riesgo de que se continuaran rectificando artículos de la ley ${ }^{8}$.

En este sentido, las acciones para lograr consolidar una radio local condensaban discursos que reivindicaban una comunicación en perspectiva que, al transversalizarse con otras demandas lcomo la tierra, por ejemplo), buscaban conjugar una dimensión más bien social del uso de las tecnologías y apostar a una construcción política constituida en torno a las necesidades y disputas de las comunidades kollas. A su vez, el proyecto comenzaba a reafirmar la "indigeneidad" cuando se reconocía que era fruto de la lucha colectiva de la organización y no de la municipalidad. El proceso se valoraba por la importancia de emplazar el estudio de transmisión en la sede de la OCAN, lo que implicaba no sólo contar con un espacio de difusión de información sino con un lugar de debate público abierto a la comunidad con incidencia local.

Bajo este escenario, el medio empezó a funcionar dando paso a una nueva etapa que permitiera desarrollar los objetivos de su emplazamiento: "constituirse como un servicio para las comunidades", "aportar a la organización territorial" y "fortalecer ese buen vivir" (Líder indígena de $\mathrm{Na}$ zareno, 2015). El proyecto se consolidó como una estrategia para visibilizar la identidad indígena kolla y los reclamos y demandas en torno a la lucha por el territorio:

Estamos convencidos que ésta va a ser una herramienta fundamental, sobre todo para la gestión territorial, porque, cuando pensamos en el tema de la radio, una de las razones era el tema de la tierra, que la radio nos sirva para estar comunicados, para estar en diálogo entre las comunidades, para que vayamos conversando, charlando y comunicando todo lo que va pasando con el tema de la gestión de las tierras. Y regularizar el tema territorial significa también apostar al tema de la identidad, significa también apostar a la revitalización de la lengua, la cultura, así que bueno, creemos que la radio va a ser fundamental (Líder indígena de Nazareno, 2015).

A partir del 2017, la OCAN comenzó a buscar otros recursos para conseguir financiamiento y decidió realizar una rifa en honor al primer cumpleaños de la radio. Logró recaudar algunos fondos para mantener la computadora, costear gastos fijos y conservar una pequeña caja de ahorros para los pagos futuros. Al mismo tiempo, un grupo de mujeres que coordinaba el medio decidió emprender la búsqueda de publicidad, ofreciendo a los negocios cercanos y a la municipalidad la venta del espacio publicitario. Con esto se comenzó a recaudar un poco más de dinero y, además, se generó interés por parte de los candidatos a concejales, diputados y senadores para realizar sus campañas políticas en 2017 y 2019, utilizando a la radio como principal medio de difusión.

Asimismo, ciertas prácticas significantes comenzaron a complejizar estas relaciones y a generar revuelo en el pueblo cuando se empezó a problematizar, mediante los programas de radio, qué implicaba autoreconocerse como "kollas". En cierta forma, estas expresiones públicas intentaban afianzar los objetivos de la organización en relación a producir una agenda mediática propia con características que pretendían reforzar marcadores de la alteridad, politizando determinadas temáticas sensibles de abordar.

Había gente que se resistía, porque muchas veces se venían a la radio para conocerme, para ver quién soy, y al ver mi aspecto me miraban y me decían “pero vos sos joven para que vos estés hablando así" o sea, hay una persona que puede venir con 
mucha más experiencia y nos puede decir "pero sos joven". O sea, algunas personas se iban contentas y otras personas seguramente decepcionadas. Muchas veces he visto a maestros, profesores que vinieron a visitarnos a la radio y la verdad que nos felicitaban porque nos decían no hay gente joven que nos digan 'yo soy kolla, soy de aqui', y que la verdad, las cosas que uno cambia las cambia por desconocimiento, pero la gente ha sido muy flexible, ha habido gente que se ha ido muy decepcionada y ha habido gente que se ha ido muy contenta (Comunicadora de la FM OCAN, 2017).

Si por ahí lo fuerte, que por ahí es no debemos bajar los brazos en cuanto a la trasmisión de los valores como pueblo o como originarios del lugar, ya que esto va a fortalecer a la identidad de nuestros hijos, porque muchas veces cuando nuestros hijos o familiares se van a la ciudad vuelven y ya no hablan las palabras que hablamos o prácticamente te ignoran (...) "dicen, pero si estamos hablando con un kolla" siendo ellos mismos también son kollas, ¿no? Eso es por ahí muy doloroso o equivocarse en una palabra y que te corrijan es por ahí algo que te va a doler tanto en el alma que una persona tuya te esté diciendo eso (Conversación al aire en la FM OCAN, 2017).

De este modo, la radio se constituyó en una oportunidad para relatar experiencias personales relacionadas a interpelaciones negativas, estigmatizantes, racistas y discriminatorias, donde los sujetos eran señalados por hablar mal, como boliviano o kolla. A partir de estos debates en la emisora, lo que se pretendía era definir y reafirmar positivamente la pertenencia étnica con fundamentos históricos, es decir, aquellos relacionados a la construcción hegemónica de un país blanco y europeo.

Asimismo, los medios de comunicación fueron herramientas que permitieron aglutinar algunos proyectos de desarrollo y fortalecer el trabajo de los agentes sanitarios desde una perspectiva integracionista. Posteriormente, primero a través de lo escrito y luego por medio de la oralidad, fueron puestos al servicio de las luchas y comenzaron como espacios para problematizar demandas locales y priorizar información sobre las asambleas y demandas territoriales.

A la par de ir construyendo, negociando y disputando, el proyecto se fue reconfigurando en función de los límites y las posibilidades de la misma organización. En el propio camino de legitimación de la FM OCAN, la organización tejió una red de alianzas entre indígenas y no indígenas, formó comunicadores populares y configuró a la indigeneidad como un elemento central para disputar sentidos: por la tierra, por la comunicación, por la identidad o, en palabras de un líder indígena, por "el buen vivir que es el tema del territorio".

\section{Conclusiones}

Este trabajo reflexiona sobre los procesos de comunicación desde la cultura y la acción política, rompiendo con el abordaje comunicacional reduccionista vinculado al mero uso de las tecnologías como herramientas de difusión e información. Para ello, reconstruimos un mapa de articulaciones entre actores estatales, religiosos e indígenas en el marco del proyecto político-comunicacional de la OCAN. Analizamos cómo la organización, al incluir la participación en los medios entre sus prioridades, configuró una serie de prácticas en torno a construir una radio propia que visibilizara cuestiones identitarias y territoriales del pueblo kolla.

Por otra parte, el esfuerzo por reflexionar sobre estos procesos de manera relacionada y no concibiendo categorías aisladas, implicó aproximarse a los Estudios sobre Comunicación Popular, implícitamente relacionados con el desarrollo de investigaciones más recientes sobre experiencias audiovisuales indígenas. Tal como recuperamos en el apartado teórico, durante el desarrollo de este campo, lo indígena aparecía mencionado de otra forma. Posteriormente, y sobre todo en estrecha vinculación con los procesos de emergencia étnica a fines del siglo $X X$, estas categorías comenzaron a desplazarse y a referir específicamente a un autoreconocimiento en tanto pueblos y/o comunidades indígenas. En cierto sentido, tal como plantean $\mathrm{Ba}$ rranquero y Tanco (2018), la comunicación indígena puede pensarse como un campo en formación que busca dar continuidad a los debates tradicionales del pensamiento comunicacional latinoamericano, aunque incluyendo particulares modos de reivindicar la identidad y el territorio por las propias comunidades. 
Desde nuestra perspectiva, concebimos a los procesos comunicacionales como instancias que atraviesan transversalmente distintos aspectos de la vida cotidiana de los sujetos y, a su vez, producen consecuencias que también alteran esa cotidianeidad. Nos referimos a cómo la trama tecnológica, guiada por dispositivos que tienen funciones que se le atribuyen o encomiendan, reproducen lógicas de producción e inserción al mercado. El desafío de este trabajo ha sido articular estas lecturas desde un abordaje empírico que permita reconstruir procesos de larga duración, además de reflexionar sobre los usos y sentidos que adquieren los medios de comunicación en distintos contextos.

La OCAN, a través de sus proyectos gráficos y radiales, buscó articular y legitimar acciones en torno a la disputa por la propiedad de las tierras. Esto no pudo ser posible sin la alianza entre actores heterogéneos, que afianzaron el desarrollo de dispositivos tecnológicos con distintos sentidos a lo largo del tiempo. En un primer momento, esto estuvo estrictamente vinculado al trabajo de los agentes sanitarios. Luego, se profundizó como estrategia organizacional cuando las condiciones históricas permitieron disputar legalmente el espectro radioeléctrico. Allí la radio, como aparato tecnocomunicativo, ha sido utilizado como canal y espacio de interlocución con funciones específicas por sus condiciones de producción sencillas, es decir, poco costosa y relativamente accesible mediante la oralidad. Su vigencia como proyecto en Nazareno se debe no sólo a estas características inclusivas que ofrece la tecnología, sino también a su potencia como práctica popular y alternativa de comunicación que permite otros modos de interactuar y construir sentido.

Al mismo tiempo, cabe señalar que este proceso se configuró en torno a varios factores que superaron la lógica instrumental del uso de los medios de comunicación y adquirió un sentido político muy vinculado a la visibilización de los derechos indígenas. Es decir, el proyecto ocupó un lugar importante para la organización, aunque por supuesto no se constituyó como lo único y exclusivo, sino que siempre estuvo en permanente articulación con procesos territoriales. En este marco, la constitución de una radio propia también capitalizó la visibilización de sujetos políticos en el espacio público mediatizado, produciendo y generando contenidos de interés para las comunidades de la zona. En palabras de un líder indígena, esto implica que:

La radio de la OCAN no solo tiene que informar, sino que se tiene que convertir en un servicio de comunicación (...) que sirva para que la gente tenga la información y que con eso pueda decidir sobre algunas cuestiones, y que además sea una herramienta para esta lucha que está teniendo la organización, por este sueño que tiene la organización por obtener el título de propiedad comunitaria. $Y$ bueno, cuando se piensa el tema de la radio uno de los fundamentos que se pone es justamente ese, que la radio ayude a comunicar (...) vaya dando paso a la obtención de ese título comunitario (Líder indígena de Nazareno, 2015).

\section{Notas}

1. Etnia que habita el noroeste de Argentina, principalmente en las provincias de Jujuy, Salta y Catamarca. Según el Ministerio de Cultura de la Nación, existen 38 pueblos indígenas en ese país. Ver https://www. cultura.gob.ar/dia-internacional-de-los-pueblosindigenas_6292/.

2. Fundación sin fines de lucro comprometida con el trabajo social de la iglesia católica, el desarrollo humano y la caridad religiosa, dependiente de la Prelatura de Humahuaca (Jujuy, Argentina).

3. Creado en 1993 por la Secretaría de Agricultura, Ganadería y Pesca de la Nación, financiado por el Banco Mundial. En 2008 se constituyó como Secretaría de Agricultura Familiar.

4. En el contexto de la provincia de Salta, lo kolla alude a connotaciones negativas, despectivas, discriminatorias, pero también reivindicativas en términos de clase, raza, etnia y frontera en Argentina lver, por ejemplo, Villagra, 2020).

5. La OCAN agrupa a más de mil familias a través de sesenta delegados que pertenecen a las veintitrés comunidades de Nazareno. Esta organización se conformó a principios de 1990 y en el año 1998 obtuvo su personería a través del Instituto Nacional de Asuntos Indígenas.

6. Estos debates se dieron en un marco de transformaciones jurídicas a nivel nacional e internacional, especialmente a partir de la reforma de Constitución Nacional de Argentina en 1994, la cual reconoció la preexistencia de los pueblos indígenas y sentó el deber de reconocer la posesión y propiedad comunitaria de las tierras.

7. Para mayor información, véase Milana \& Villagra (2020). 
8. Mediante dos Decretos de Necesidad y Urgencia (DNU 13/2015 y 267/2015), se creó el Ministerio de Comunicaciones y AFSCA fue reemplazada por el Ente Nacional de Comunicaciones (ENACOM). Como exponen Longo et al., (2017), las modificaciones que se realizaron redujeron la cantidad de representan- tes del tercer sector - de tres personas a una- en el Consejo Federal de Comunicación Audiovisual (COFECA), el cual fue eliminado y reemplazado por el Consejo Federal de Comunicación (COFECO), incluyendo al Consejo Federal de Tecnologías de las Telecomunicaciones y la Digitalización.

\section{Referencias}

Andrada, D. (2019). Hacia un periodismo indígena. Buenos Aires: Ediciones Universidad del Salvador.

Barranquero, A. \& Tanco, E. (2018). Editorial. Comunicación Indígena en América Latina. Anuario Electrónico de Estudios de Comunicación Social, 11 (2), 5-11. https://doi.org/10.12804/ revistas.urosario.edu.co/disertaciones/11.2.2018

Belotti, F. (2018). Los medios de comunicación de los pueblos originarios frente a la Ley de Servicios de Comunicación Audiovisual: experiencias, contradicciones, desafíos. Informe de investigación (2016-2017). Buenos Aires: Universidad Nacional de Quilmes.

Doyle, M. M. (2013). Los medios de comunicación en las luchas de los pueblos indígenas. Abordaje desde los estudios sobre comunicación en América Latina. (Tesis de Maestría, Universidad Nacional de Córdobal.

Doyle, M. M. (2016). El derecho a la comunicación de los pueblos originarios. Límites y posibilidades de las reivindicaciones indígenas en relación al sistema de medios de comunicación en Argentina. (Tesis de Doctorado Universidad Nacional de Buenos Aires).

Doyle, M. M. (2018). Las luchas por territorios ancestrales en los medios indígenas. El caso de FM La Voz Indígena. Comunicación y Medios, (38), 177-189. http://dx.doi.org/10.5354/07191529.2018.50650

Fasano, P. (2015). La investigación en comunicación comunitaria y popular: el uso de la etnografía como enfoque. AVATARES de la comunicación y la cultura, (10), 1-8.

Festa, R. et al. (1986). Comunicación popular y alternativa. Buenos Aires: Ediciones Paulinas.

Gordillo, G. \& Hirsch, S. (2010). Movilizaciones indígenas e identidades en disputa en Argentina: historias de invisibilización y re-emergencia. Buenos Aires: Editorial La Crujía

Guber, R. (1991). El salvaje metropolitano. Buenos Aires: Legasa.

Guber, R. (2001). La etnografía: método, campo y reflexividad. Bogotá: Grupo Editorial Norma.

Guzmán, H. (2011). La participación en los Foros por una nueva Ley de Servicios de Comunicación Audiovisual en Argentina. El caso de los pueblos indígenas/originarios. Revista derecom. Nueva Época, (7), 1-16.

Herrera Miller, K. (2006). ¿Del grito pionero... al silencio? Las radios sindicales mineras en la Bolivia de hoy. Plural Editores: La Paz.

Kejval, L. (2009). Truchas: Los proyectos políticos-culturales de la radios comunitarias, alternativas y populares argentinas. Buenos Aires: Prometeo.

Lizondo, L. (2015). Comunicación con identidad o comunicación comunitaria. El caso de la FM La Voz Indígena. (Tesis de Maestría, Universidad Nacional de La Plata).

Lizondo, L. (2017). Escenario multilingüe, poroso y de disputa territorial: la comunicación con identidad en FM Comunitaria La Voz Indígena de Tartagal. Revista RevCom. Año 3, (5), 22-33. 
Longo, V. et al. (2017). Regresión. Las nuevas políticas para medios comunitarios en Argentina. Revista Logos: Comunicação e Universidade, 24 (1), 37-51.

Martín-Barbero, J. (1983). Comunicación popular y los modelos transnacionales. Entrevista. Chasqui, Revista Latinoamericana de Comunicación, (8), 4-11.

Martín-Barbero, J. (1987). De los medios a las mediaciones. Comunicación, cultura y hegemonía. México: Editorial Gustavo Gili S.A.

Martínez, A.; Müller, A. \& Rubino, A. (2007). Nazareno en el aire. Sistematización de una experiencia de Comunicación Popular. (Tesis de Licenciatura en Comunicación Social, Universidad Nacional de Córdoba).

Mata, M. C. (2015). Los lugares incómodos lo las deudas-desafíos de las carreras de Comunicación). Chasqui. Revista Latinoamericana de Comunicación, (129), 17-35.

Milana, M. P. \& Villagra, E. (2020). Entre prácticas de intervención y proyectos de desarrollo. Un acercamiento a los procesos organizativos indígenas en los valles interandinos (Salta, Argentina). Revista Territorios (42), 1-29. https://doi.org/10.12804/revistas.urosario. edu.co/territorios/a.7609

Noro, A. F. (2012). Radio "Pachacuti”: Primera radio Fm Indígena de la Argentina. Revista Question, (35), 401-410.

Pulleiro, A. (2012). La radio alternativa en América Latina. Experiencias y debates desde los orígenes hasta el siglo XXI. Buenos Aires: Cooperativa Gráfica El Río Suena.

Salazar, J. F. (2002). Activismo indígena en América Latina: estrategias para una construcción cultural de las tecnologías de información y comunicación. Journal of Iberian and Latin American Studies, Vol. 8(2), 61-80. https://doi.org/10.1080/13260219.2002.10431783.

Schmucler, H. (1984). Un proyecto de Comunicación/Cultura. Comunicación y Cultura (12), 1-6.

Siares, E. \& Belotti, F. (2018). Los medios indígenas en Argentina: caracterización v desafíns a partir de la experiencia de dos radios kollas. Anuario Electrónico de Estudios en Comunicación Social “Disertaciones”, Vol. 11(2), 86-103. http://dx.doi.org/https://doi. org/10.12804/revistas.urosario.edu.co/disertaciones/a.5706

Villagra, E. (2020) Comunicación, política y alteridad. Los procesos político-comunicacionales de una organización indígena kolla en la provincia de Salta (1980-2020). (Tesis de Doctorado. Universidad Nacional de Córdoba).

\section{- Sobre la autora:}

Emilia Villagra es Licenciada en Ciencias de la Comunicación (UNSa) y Doctoranda en Ciencia Política (UNC). Becaria doctoral del CONICET. Integra el proyecto de investigación "Las tramas sociales en la construcción de las diversas vías del desarrollo: estudio sobre experiencias comunitarias y su articulación con la formulación de políticas públicas" (UNC).

\section{- ¿Cómo citar?}

Villagra, E. (2021). Los procesos político-comunicacionales de una organización indígena en Salta, Argentina. Comunicación y Medios, (43), 115-126.

https://doi.org/10.5354/0719-1529.2021.58759 